\title{
Microstructural and Conductivity Comparison of Ag Films Grown on Amorphous $\mathrm{TiO}_{2}$ and Polycrystalline $\mathrm{ZnO}$.
}

\section{Rand Dannenberg ${ }^{\mathrm{a}}$, Eric Stach ${ }^{\mathrm{b}}$, Darin Glenn ${ }^{\mathrm{a}}$, Peter Sieck ${ }^{\mathrm{a}}$, Kyle Hukari $^{\mathrm{a}}$}

${ }^{a}$ AFG Development Corporation, 1311 Clegg Street, Suite B, Petaluma, CA

94954 Phone: 707-762-6490 E-mail: rand.dannenberg@afg.com

${ }^{b}$ National Center for Electron Microscopy, Lawrence Berkeley Lab, Blgd. 72 , Berkeley CA 94720 Phone: 510-486-4634 E-mail: eastach@lbl.gov

\begin{abstract}
Ag films were sputter deposited onto amorphous $\mathrm{TiO}_{2}$ underlayers $25 \mathrm{~nm}$ thick, and also amorphous $\mathrm{TiO}_{2}(25 \mathrm{~nm}) / \mathrm{ZnO}(5 \mathrm{~nm})$ multiunderlayers. The substrates were back-etched Si with a $50 \mathrm{~nm}$ thick LPCVD $\mathrm{Si}_{3} \mathrm{~N}_{4}$ electron transparent membrane. The $\mathrm{ZnO}$, sputtered onto amorphous $\mathrm{TiO}_{2}$, formed a continuous layer with a grain size of $5 \mathrm{~nm}$ in diameter, on the order of the film thickness. There are several microstructural differences in the $\mathrm{Ag}$ dependent on the underlayers, revealed by TEM. First a strong $\{0001\} \mathrm{ZnO}$ to $\{111\} \mathrm{Ag}$ fibre-texture relationship exists. On $\mathrm{TiO}_{2}$ the $\mathrm{Ag}$ microstructure shows many abnormal grains whose average diameter is about $60-80 \mathrm{~nm}$, whereas the films on $\mathrm{ZnO}$ show few abnormal grains. The background matrix of normal grains on the $\mathrm{TiO}_{2}$ is roughly $15 \mathrm{~nm}$, while the normal grain size on the $\mathrm{ZnO}$ is about 25 $\mathrm{nm}$. Electron diffraction patterns show that the film on $\mathrm{ZnO}$ has a strong $\{111\}$
\end{abstract}


orientation, and dark field images with this diffraction condition have a grain size of about $30 \mathrm{~nm}$. In a region near the center of the TEM grid where there is the greatest local heating during deposition, Ag films grown on amorphous $\mathrm{TiO}_{2}$ are discontinuous, whereas on $\mathrm{ZnO}$, the film is continuous. When films $8 \mathrm{~nm}$ films are grown on solid glass substrates, those with $\mathrm{ZnO}$ underlayers have sheet resistances of $5.68 \Omega /$, whereas those on $\mathrm{TiO}_{2}$ are $7.56 \Omega /$, and when $16 \mathrm{~nm}$ thick, the corresponding sheet resistances are $2.7 \Omega /$ and $3.3 \Omega /$. The conductivity difference is very repeatable. The improved conductivity is thought to be a combined effect of reduced grain boundary area per unit volume, the predominance of low grain boundary resistivity Coincidence Site Lattice boundaries from the $\mathrm{Ag}\{111\}$ orientation, and $\mathrm{Ag}$ planarization on $\mathrm{ZnO}$ resulting in less groove formation on deposition, concluded from atomic force microscopy. 


\section{Introduction.}

Zinc Oxide underlayers are known to enhance the conductivity of Ag films. Macroscopically measured quantities, such as sheet resistance changes, have been recorded as a function of the film thicknesses of the underlayers and the $\mathrm{Ag}$ thickness [1,18]. For the same Ag thickness, the sheet resistance will fall as the thickness of the $\mathrm{ZnO}$ underlayer is increased to about $6 \mathrm{~nm}$. It has been found that the percentage of conductivity enhancement is diminished as the $\mathrm{Ag}$ thickness increases [2].

The anecdotal explanation for the conductivity enhancement is diminished $\mathrm{Ag}$ film roughness, resulting in less electron scattering from the interfaces at either the top or bottom of the film. However, there are several other mechanisms that may result in conductivity enhancement due to the underlayer. 1) More shallow thermal grooves from improved wetting will lead to a greater average geometrical thickness. 2) Greater grain sizes will result in less grain boundary area per unit volume and therefore less grain boundary resistivity. 3) Strong film orientation effects can result in less grain to grain scattering. For example, Coincidence Site Lattice (CSL) boundaries will predominate for $\{111\}$ oriented FCC metals, and CSL boundaries are known to have lower grain boundary resistivities from less associated translational symmetry loss across the interfaces [3,4].4) Less atomic 
level structural disorder for larger grained materials, from reduced long range atomic level strain fields from finite sized grain boundaries [17].

Little information was available on the microstructure of $\mathrm{Ag}$ films grown on $\mathrm{ZnO}$ underlayers until very recently where it was shown using x-ray diffraction that a fibre-texture orientation relationship exists between (0002) $\mathrm{ZnO}$ and (111) $\mathrm{Ag}$ [Arbab, 18]. In this letter, we argue that several of the aforementioned microstructural differences may be present, and that it remains to be seen what the greatest factor in the conductivity enhancement is.

\section{Experimental Procedure.}

$8 \mathrm{~nm} \mathrm{Ag}$ films were planar-DC sputter deposited onto amorphous $\mathrm{TiO}_{2}\left(\mathrm{a}-\mathrm{TiO}_{2}\right)$ underlayers $25 \mathrm{~nm}$ thick, and also a- $\mathrm{TiO}_{2}(25 \mathrm{~nm}) / \mathrm{ZnO}(5 \mathrm{~nm})$ multi-underlayers. The substrates were back-etched Si with $50 \mathrm{~nm}$ thick LPCVD amorphous $\mathrm{Si}_{3} \mathrm{~N}_{4}$ electron transparent membranes, Figure 1, and bulk glass. $16 \mathrm{~nm}$ thick Ag films were prepared on the same underlayers for AFM analysis. The dielectric layers were reactively sputtered from metal targets with $\approx 40 \mathrm{kHz}$ planar TwinMag ${ }^{\mathrm{Tw}}$ technology [1]. A sample of $\mathrm{TiO}_{2} / \mathrm{ZnO}$ with $\mathrm{ZnO}$ thickness of $25 \mathrm{~nm}$ was made to get a strong electron diffraction ring pattern of the $\mathrm{ZnO}$. 
For the samples on glass, film thickness was measured with a KLA-Tencor AlphaStep 500 profilometer, and sheet resistance was measured with a calibrated NAGY SRM-10 inductance meter. The TEM analysis was performed in a JEOL $200 \mathrm{CX}$ operating at $200 \mathrm{kV}(\lambda=0.002507 \mathrm{~nm})$. Diffraction patterns were collected with a camera length of $82 \mathrm{~cm}$.

\section{Data.}

Figure 8 shows that the $\mathrm{TiO}_{2}$ is amorphous, as no sharp rings exist in the electron diffraction pattern. Figure 2 shows the electron diffraction pattern comparison for the Ag film grown on the two types of underlayers. Two methods were used to verify that the dark ring of the pattern corresponding to the $\mathrm{Ag}$ film grown on the $\mathrm{ZnO}$ is of the type $\{220\}$. First, an absolute measurement of the ring radii using the wavelength and camera length mentioned in section II yielded a d-spacing of $1.468 \mathrm{~A}$. Second, the spots on the left hand side are those of [001] Si from the membrane support structure, and the inverse of the radius of the spots closest to the dark ring are of the type $\{400\}$ with a $1.357 \mathrm{~A}$ theoretical $d-$ spacing. This provides an internal calibration, and the extracted d-spacing for the $\mathrm{Ag}$ dark ring is $1.453 \mathrm{~A}$. Both these values for the $\mathrm{Ag}$ dark ring $\mathrm{d}$-spacing are close to the theoretical value for $\{220\} \mathrm{Ag}$ of $1.446 \mathrm{~A}$.

Since the $[2,-2,0]$ plane is perpendicular to the [111] plane in a cubic lattice and the diffraction vectors are in the plane of the film, we expect a strong $\{220\}$ ring 
when the film is strongly $\{111\}$ oriented. Therefore, we conclude that the film is $\{111\}$ oriented when grown on $\mathrm{ZnO}$, and more randomly oriented when grown on $\mathrm{a}-\mathrm{TiO}_{2}$.

Figure 3 shows the a- $\mathrm{TiO}_{2} / \mathrm{ZnO}$ underlayer diffraction pattern, and $\mathrm{a}-\mathrm{TiO}_{2} / \mathrm{ZnO} / \mathrm{Ag}$ pattern. The $\mathrm{ZnO}$ is clearly polycrystalline, with a grain size on the order of $5 \mathrm{~nm}$. Both of these diffraction patterns are indexed fully in Tables I-II. All rings visible in the $\mathrm{TiO}_{2} / \mathrm{ZnO}$ pattern are from reflections normal to Wurtzite $\{0001\} \mathrm{ZnO}$, and in the $\mathrm{TiO}_{2} / \mathrm{ZnO} / \mathrm{Ag}$ pattern, all rings present are either $\mathrm{ZnO}$ rings or from reflections normal to FCC $\{111\}$ Ag. Therefore, there exists a strong orientation relationship between $\{0001\} \mathrm{ZnO}$ and $\{111\} \mathrm{Ag}$.

Figure 4 shows the bright field images of the Ag on the two types of underlayers. One sees immediately the more abnormal microstructure for the film grown on a$\mathrm{TiO}_{2}$, and the more normal microstructure for the one on $\mathrm{ZnO}$. The average normal grain size on the $\mathrm{ZnO}$ is about $25 \mathrm{~nm}$, whereas on the a- $\mathrm{TiO}_{2}$, the normal matrix grains are about $15 \mathrm{~nm}$ in diameter.

The $\{220\}$ reflections are compared in the dark field negative of Figure 5. Clearly, the $\{111\}$ oriented grains giving rise to the strong $\{220\}$ reflections have significantly larger average grain sizes on $\mathrm{ZnO}$, near 2 to 3 times as large as grains of the same orientation on $\mathrm{a}-\mathrm{TiO}_{2}$. 
In Figure 6 it can be seen that on the $\mathrm{a}-\mathrm{TiO}_{2}$ underlayer, the $\mathrm{Ag}$ film becomes discontinuous close to the center of the TEM grid. The discontinuity is not present in the Ag film grown on the $\mathrm{ZnO}$ underlayer. We expect the local temperature to be higher in the center of the TEM grid due to the increased thermal isolation there during the film deposition. As the edge of the membrane is approached, the film becomes fully continuous again. Near the center of the grid can be seen a grayish haze from the scattering of light from the rough surface.

The sheet resistance of the films, measured when the substrate is bulk glass, was found to be $5.68 \Omega$ / with the $\mathrm{ZnO}$ underlayer, whereas those on $\mathrm{a}-\mathrm{TiO}_{2}$ are $7.56 \Omega /$, for $8 \mathrm{~nm}$ thick $\mathrm{Ag}$, and $2.7 \Omega /$ and $3.3 \Omega /$ when $16 \mathrm{~nm}$ thick. Our expectation is that the films are continuous on glass, since there is no visual haze, and the films are being deposited on a heat sink even larger than the TEM grid edge.

We show the results of atomic force microscopy (AFM) in Figs. 9-10. Clearly, the surface roughness in the presence of $\mathrm{ZnO}$ is reduced, Table III. Figure 11 shows the relationship between sheet resistance $\Re$ and the normal emissivity $\varepsilon$, and this relationship differs trivially with the underlayer type. Figure 12 shows that the $\Re$ for $\mathrm{Ag}$ on $\mathrm{ZnO}$ is consistently lower than when grown on a- $\mathrm{TiO}_{2}$, Figure 13 shows for both underlayers that $\Re_{f} / \Re_{o}=\left(h_{o} / h_{f}\right)^{3 / 2}$ where $h_{o}$ and $h_{f}$ are the old and new thicknesses of $\mathrm{Ag}$, based on linespeed. Figures 12 and 14 show that the advantageous effect of $\mathrm{ZnO}$ on $\Re$ and $\varepsilon$ grows very small as the Ag thickness 
increases. Finally, Figure 15 shows a plot of $\Re h$ vs. $2 / h$ for Ag sputtered with some $\mathrm{N}_{2}$ and $\mathrm{O}_{2}$ mixed with the primary process gas, $\mathrm{Ar}$, which is interpreted in the discussion.

\section{Discussion.}

There are several microstructural differences in the Ag films when deposited on $\mathrm{ZnO}$. The increased grain size and the $\{111\}$ orientation effects may be responsible for the reduced sheet resistance.

In metals, scattering of electrons by grain boundaries contributes to the overall electrical resistivity of the polycrystal. Both bulk metals and metal films have specific grain boundary resistivities, $\delta \rho_{s p}$, typically between $10^{-15}$ to $10^{-16} \Omega-\mathrm{m}^{2}[5$ 8]. For example, the $\delta \rho_{s p}$ for good conductoring films such as $\mathrm{Cu}, \mathrm{Au}$ and $\mathrm{Al}$ are $1.8 \times 10^{-16} \Omega-\mathrm{m}^{2}, 3.5 \times 10^{-16} \Omega-\mathrm{m}^{2}$ and $1.1 \times 10^{-16} \Omega-\mathrm{m}^{2}$, respectively. The $\delta \rho_{s p}$ for bulk samples tends to be higher than for film samples, $\delta \rho_{s p}$-bulk $\sim 1.5 \times \delta \rho_{s p}$-film, and this is likely due to the predominance of oriented grains and/or small angle tilt boundaries in films $[3,5,8]$. To compute the contribution of grain boundaries to the total resistivity, one must multiply $\delta \rho_{s p}$ by the grain boundary area per unit volume, $\xi$. The total resistivity of the system is given by

$\rho_{\text {tot }}=\rho_{\text {bulk }}+\delta \rho_{s p} \cdot \xi$ 
where $\xi=\mathrm{C} / \mathrm{s}, \mathrm{s}$ is the grain diameter, $\mathrm{C} \sim 1$ to 3 is a geometrical constant, and the bulk resistivity $\rho_{\text {bulk }}=1.6 \mu \Omega-\mathrm{cm}$ for $\mathrm{Ag}$ [20]. The value of $\mathrm{C}$ depends on the microstructure and assumptions about which boundaries contribute to scattering. For example, consider the simple case of cube shaped grains where $s<<$, where $\mathrm{h}$ is the film thickness. If all boundaries contribute to the scattering, $\xi=(1 / 2) 6 / s=3 /$ s where $C=3$. If only boundaries perpendicular to the current, contribute, $\mathrm{C}=2$. In a columnar structure where $s \geq h$, if only boundaries perpendicular to the current contribute, $\mathrm{C}=1$, and if all 4 sides contribute, $\mathrm{C}=2$. Brown has shown that boundaries whose dislocations have the line-sense perpendicular to the current seem to matter the most, so for $s \geq h, C$ is between 1 and $2[5]$.

For nanocrystalline films, the grain boundary resistivity contribution is very significant, and this is shown in Figure 7, where we used $\mathrm{C}=2$, an $\mathrm{Ag}$ thickness of $h=8 \mathrm{~nm}$, and $\delta \rho_{s p}=3.5 \times 10^{-16} \Omega-\mathrm{m}^{2}$. We ask what $\delta \rho_{s p}$ would be needed to account for the reduced sheet resistance in $\mathrm{Ag}$, and we have selected a value close to that of the $\delta \rho_{s p}$ of Au films because of the similar electron shell filling and electrical properties. In Figure 7, the sheet resistance $\mathfrak{R}=\rho_{\text {tot }} / \mathrm{h}$. For our system, $\mathrm{s}$ $\approx 15 \mathrm{~nm}$ on $\mathrm{a}-\mathrm{TiO}_{2}$ and $\mathrm{s} \approx 25 \mathrm{~nm}$ on $\mathrm{ZnO}$, therefore $\mathrm{s} \geq \mathrm{h}$. This would correspond to sheet resistances of $5.5 \Omega /$ and $7.83 \Omega /$ respectively. This is in good agreement with the $8 \mathrm{~nm}$ thick $\mathrm{Ag}$ with a reasonable choice of $\delta \rho_{s p}$ for the film. 
We may compare our value of grain boundary resistivity of Ag used above to one calculated from free-electron theory. Ag is very free electron-like, since it has no partially filled $d$ or $f$ shells, a single 5 s valance electron, and $d$-bands far below the Fermi energy. We will use the reflection coefficients from Shaztkes (1973) for epitaxial Ag twin boundaries of $R=0.14$, discussed in Brown [5]. The ratio of the free electron radius to lattice constant $r_{s} / a_{o}=3.02 \mathrm{in} \mathrm{Ag}$, the resistivity of bulk $\mathrm{Ag}$ at room temperature is $1.6 \mu \Omega-\mathrm{cm}$, so the room temperature mean free path $l=$ $\left(r_{s} / a_{o}\right)^{2} / \rho \times 9.2 \mathrm{~nm}=52.4 \mathrm{~nm}[19,20]$. We then use the Shatzkes expression $\delta \rho_{s p}$ $=0.75 \rho l R(1-R)^{-1}=1.024 \times 10^{-16} \Omega-\mathrm{m}^{2}[5]$. This represents a lower limit on the $\mathrm{Ag}$ film $\delta \rho_{s p}$ because it assumes that the all the boundaries are twins with $R=0.14$. However, this theoretical value is too low to account for the conductivity enhancement. For the same $R$, if the corresponding Au values are substituted, we find $\delta \rho_{s p}=1.018 \times 10^{-16} \Omega-\mathrm{m}^{2}$, virtually the same value as $\mathrm{Ag}$. To arrive at the literature value of $\delta \rho_{s p}=3.5 \times 10^{-16} \Omega-\mathrm{m}^{2}$ for $\mathrm{Au}, R=0.36$ is required.

The resultant $\{111\}$ orientation is significant. In the film grown on $\mathrm{ZnO}$, the grain size is roughly twice that of the film thickness, and so the structure is columnar. In a columnar $\{111\}$ oriented FCC metal film, such as Ag, it has been shown that all grain boundaries are Coincidence Site Lattice (CSL) boundaries [3]. CSL boundaries have lower interfacial energies, lower specific volume expansions, and preserve some of the translational symmetry across the interface. The net result is that the $\delta \rho_{s p}$ for CSL boundaries tends to be lower than non-CSL boundaries [4]. For example, the work of Nakamichi shows that in aluminum 
small angle and large angle boundaries have $3 \times 10^{-16}<\delta \rho_{s p}<5 \times 10^{-16} \Omega-\mathrm{m}^{2}$, whereas the CSL boundaries have $3 \times 10^{-17}<\delta \rho_{s p}<3.5 \times 10^{-16} \Omega-\mathrm{m}^{2}$. Therefore, the CSL boundary is typically at the lower limit of the non-CSL boundary values, and with a range of up to a factor of 20 lower [4].

Birringer has shown in nanocrystalline $\mathrm{Pt}$, that the resistivity begins to fall off much more rapidly once the grain size reaches about $10 \mathrm{~nm}$ or more [19]. Associated with this decrease is a rapid decrease in the atomic level strain, theorized to be caused by the disappearance of the strain fields of grain boundary disclination dipoles as the boundaries take on a less finite size character. Although we have made no attempt to measure this, we mention this as another possible influence of increased as deposited grain sizes in our films on $\mathrm{ZnO}$.

Surface roughness also plays an important role in films, because for the same volume of material, a rougher surface corresponds to thinner a continuous portion of total film mass for conduction of electrons. It appears likely that the film grown on $\mathrm{a}-\mathrm{TiO}_{2}$ is rougher, in light of Figs 6, 9-10. The presence of $\mathrm{ZnO}$ does cause the Ag to better wet the substrate, so one may expect that the grain boundaries in the more continuous regions form shallower thermal grooves during deposition heating. 
Roughness effects do appear to dominate in Ag films grown at fixed temperatures and increasing cathode powers. It is demonstrated in one paper that the grain size, surface roughness, and resistivity simultaneously decrease with increasing power and fixed substrate temperature [9]. This grain sizeresistivity dependence is of course opposite to what we have proposed, suggesting the domination of surface roughness reduction. However, the range of surface roughnesses that can be generated in such an experiment is much greater than in our case, since the power directly impacts the range over which adatoms can migrate by surface diffusion before they are buried. Another roughness contribution with changing power is the enhancement of non-normal sputtered fluxes which give rise to self-shadowing of the growing film.

We attempt to calculate the expected increased emissivity of the roughened surface using accepted theory, AFM data from Table III for $16 \mathrm{~nm} \mathrm{Ag}$ films, and sheet resistance measurements. According to Szczyrbowski [1]

$\varepsilon_{r}=\varepsilon_{s} A\left[1+(A-1) \varepsilon_{s}\right]^{-1}$

$$
A=S_{r} / S_{S}
$$

where $\varepsilon_{r}$ is the emissivity of the roughened surface, $\varepsilon_{s}$ is the emissivity of the flat smooth surface, $S_{r}$ is the total surface area of the rough surface with the experimental values shown in Table III, and $S_{s}$ is the area of the smooth flat 
surface, which in this case is $4 \mu \mathrm{m}^{2}$. To relate sheet resistance to emissivity $[1,16]$

$\varepsilon \approx \eta \Re+\beta$

where $\mathfrak{R}$ is sheet resistance in $\Omega /$ with $(\eta, \beta)_{\mathrm{ZnO}}=(0.0140 / \Omega, 0.0118)$ and $(\eta, \beta)_{\mathrm{TiO2}}=(0.0134 / \Omega, 0.0132)$. The latter applies for $2 \Omega<\Re<9 \Omega /$ Figure 11. $A_{\max }=S_{r, \max } / S_{s}$, so from Table III, $A=4.066 / 4=1.0165$, or an increase in area of only $1.65 \%$. From Equation $2, \varepsilon_{r} / \varepsilon_{s} \cong A \cong 1$. However, $\varepsilon_{r} / \varepsilon_{s}=1.19$, a somewhat larger emissivity change than expected based on the change in $A$.

The AFM images suggest there is a markedly reduced continuous thickness available for conduction on the Ag films grown on a- $\mathrm{TiO}_{2}$. If $\Re=\rho / h_{c}$, where $\rho$ is the resistivity, and the continuous thickness $h_{c}=h_{o}-r_{r m s} / 2$. The mean film thickness is $h_{0}=16 \mathrm{~nm}$ from profilometry and the $r_{r m s}$ is the root-mean-square roughness. $\mathfrak{R}_{r} / \mathfrak{R}_{s}=h_{c s} / h_{c r}$. However, from Table III, $h_{c s} / h_{c r}=1.05$ and $\Re_{r} / \Re_{s}=$ 1.22, a somewhat larger resistivity change than expected from our simple model. If we use $\Re_{r} / \Re_{s}=\left(h_{c s} / h_{c r}\right)^{3 / 2}$ based on the data of Figure 12, we find $\left(h_{c s} / h_{c r}\right)^{3 / 2}=$ 1.075 , which is closer but still too small.

An interesting result is that when $\mathrm{Ag}$ is deposited with the same deposition conditions onto either $\mathrm{TiO}_{2}$ or $\mathrm{ZnO}$ approaches the same final sheet resistance after a heat treatment. Ag films about $26 \mathrm{~nm}$ thick with sheet resistances of 2.4 
$\Omega /$ on $\mathrm{ZnO}$ and $3.0 \Omega /$ on $\mathrm{TiO}_{2}$ have sheet resistances of $2.0 \Omega /$ after a 4 minute tempering process in low-emissivity optical coatings. Our interpretation of this is that both films approach similar grain sizes and bulk resistitivies. This prompts us to write the equation

$$
\mathfrak{R h}=\rho_{\text {bulk }}+\delta \rho_{s p}(2 / s)
$$

If we are correct in assuming $s \cong 2 h$, as has been observed for $8 \mathrm{~nm}$ thick $\mathrm{Ag}$ on $\mathrm{TiO}_{2}$, then plots of $\mathfrak{R h}$ vs. $2 / h$ should be linear, with the slope and intercept interpretable from Equation 5. We find in Figure 15 that this is the case for a variety of process gas mixtures in Ag. Twice the slope is the boundary resistivity and the intercept is the bulk resistivity of the crystallites. Note from Table IV, that the intercepts are higher than the bulk resistivity for $\mathrm{Ag}$ given in the CRC handbook as $1.6 \times 10^{-8} \Omega-\mathrm{m}$. The larger values for the latter may be due to atomic disorder, gas incorporation, strain, etc. Note also that the twice the slope for $\mathrm{Ag}$ sputtered without $\mathrm{O}_{2}$ in the process gas is rather close to the specific boundary resistivity of Au, Table IV. If we use $\delta \rho_{s p}$ and $\rho_{\text {bulk }}$ from Table IV for Ag deposited without $\mathrm{O}_{2}$ onto $\mathrm{TiO}_{2}$ and $\mathrm{ZnO}$ and substitute these into Equation 1, we find for the grain sizes on $\mathrm{TiO}_{2}$ and $\mathrm{ZnO}(15 \mathrm{~nm}$ and $25 \mathrm{~nm}), 9.74 \Omega /$ and $6.33 \Omega /$, respectively, or $\Re_{r} / \Re_{s}=1.54 .5 .68 \Omega /$ and $7.56 \Omega /$ are what is actually observed where $\mathfrak{R}_{r} / \mathfrak{R}_{S}=1.33$ so the simple model results in a larger difference than actually measured. Table $V$ summarizes the ratios of models to the measured values. 
At this time, it is unclear what aspect of the $\mathrm{ZnO}$ causes the improved wettability of the Ag. It could be that the surface energy of all orientations of $\mathrm{ZnO}$ is closer to that of the $\mathrm{Ag}$, or that the $\mathrm{ZnO}$ is oriented and there is a lattice match to $\{111\} \mathrm{Ag}$ which results in better adhesion. Generally, the substrate need not have a well oriented plane or a similar atomic structure for an oriented film to grow, as oriented films have been grown on plastics and amorphous substrates [10-11]. In FCC structures, the films orient by the simple virtue of the high symmetry of the close-packed $\{111\}$ plane in cubic crystals.

An interesting aside is that the $\{111\}$ oriented $\mathrm{Ag}$ deposited in a glass $/ \mathrm{TiO}_{2} / \mathrm{ZnO} /\{111\} \mathrm{Ag} / \mathrm{Si}_{3} \mathrm{~N}_{4}$ system is more corrosion resistant in high relative humidity than glass $/ \mathrm{TiO}_{2} /\{$ random $\} \mathrm{Ag} / \mathrm{Si}_{3} \mathrm{~N}_{4}$. This finding is consistent with the results of Ando et. al., where glass/ZnO/\{111\} Ag/ZnO withstood corrosion tests better than glass $/ \mathrm{SnO}_{2} /\{$ random-amorphous $\} \mathrm{Ag} / \mathrm{ZnO}$ [12]. This suggests that the underlayer resulting in the orientation is responsible for the durability. The chemistry of such systems is complex and difficult to assess or predict based on first principles. A chemical effect may be responsible. More examples are needed to test this $\{111\}$ orientation concept versus the chemical environment.

ZnO films are well known to grow with the Wurtzite HCP structure with (0001) orientation, and this orientation promotes a $\{111\}$ orientation in Pt films [13-14]. The Pt lattice constant is $3.92 \mathrm{~A}$, and the lattice constant of $\mathrm{Ag}$ is 4.09 , so is still a 
fairly good match for expitaxy. The orienting of $\mathrm{Ag}$ on $\mathrm{ZnO}$ has been used as the key issue in a patent for low-emissivity coatings by PPG industries, although it is not explicitly stated that their $\mathrm{Ag}$ is $\{111\}$ oriented, and that the improved film qualities are a direct result of this orientation [15].

If the $\mathrm{ZnO} /\{111\} \mathrm{Ag}$ is indeed induced by hetero-epitaxy on the $\mathrm{ZnO}(0001)$ plane, then the improved wettability of $\mathrm{Ag}$ on $\mathrm{ZnO}$ is explained. This is because the surface energies of (0001) $\mathrm{ZnO}$ and $\{111\} \mathrm{Ag}$ are very similar because of the similar atomic structures. One may imagine that in the limit of equal surface energies the wetting of film to substrate must be perfect. For example Ag films being deposited on a $\{111\}$ oriented Ag "substrate" would wet perfectly. The similar atomic structure promotes wetting and better adhesion.

\section{Conclusions.}

$8 \mathrm{~nm}$ thick $\mathrm{Ag}$ films grown on $\mathrm{ZnO}$ are $\{111\}$ oriented, have very few abnormal grains, have a grain size of about $25 \mathrm{~nm}$, and a $5.68 \Omega /$ sheet resistance. Grown on amorphous $\mathrm{TiO}_{2}$, the film is randomly oriented, the matrix grains are about $15 \mathrm{~nm}$ in diamteter with a larger density of abnormal grains, and a $7.56 \Omega /$ sheet resistance. 
The change in grain size may be enough to explain the sheet resistance difference because of the nanocrystalline grain sizes, if the speicific grain boundary resistivity of these films of $\mathrm{Ag}$ is close to that of $\mathrm{Au}$ films, $3.5 \times 10^{-16} \Omega$ $\mathrm{m}^{2}$. The specific grain boundary resistivity deduced from $\Re h$ vs. $2 / h$ plots is indeed close to this value, so we feel the majority of the effect can be explained by a grain size increase when deposited on $\mathrm{ZnO}$. There is a possible bulk resistivity increase over literature values which makes the resistivity ratios between $\mathrm{Ag}$ grown on $\mathrm{ZnO}$ and $\mathrm{TiO}_{2}$ predicted to be even larger than experiment, and this discrepancy has not been resolved. Despite this offset, the agreement between the slope of the $\Re h$ vs. $2 / h$ and the Au specific boundary resistivity is encouraging.

The grain size differences may act in conjunction with the impact of reduced surface roughness to enhance the Ag film conductivity when there is an underlayer of $\mathrm{ZnO}$. Our simple mathematical treatments suggest that grain boundaries have a larger impact on the sheet resistance differences.

The $\{111\}$ Ag orientation is most likely due to hetero-epitaxial growth on (0001) oriented $\mathrm{ZnO}$. The orientation is probably responsible for the increased grain size, since $\{111\}$ oriented grains will grow at the expense of all other orientations. It also seems likely that the $\{111\}$ orientation could be related to a decreased surface roughness, since the film is composed of crystallites where the only rotations between them are in the plane of the film and all grains compete equally 
for space. The good lattice match may explain the improved wetting of $\mathrm{Ag}$ and resistance to corrosion on $\mathrm{ZnO}$.

Lastly, we are able to present some useful fitting formulas for sheet resistance, emissivity, and thickness relationships for thin film Ag. Equation 5 and the relation $\Re_{f} / \Re_{0}=\left(h_{o} / h_{f}\right)^{3 / 2}$ should be useful to workers in the field.

\section{Acknowledgements.}

Thanks to Alexander King (head of Purdue University MSE), and Joe Countrywood for helpful discussions. Thanks to Prof. Tims Sands and UC Berkeley and Prof. Richard Gambino at SUNY Stony Brook. The work at NCEM was supported by the Director, Office of Energy Research, Office of Basic

Energy Sciences, Materials Science Division of the U.S. Department of Energy under Contract No. DE-AC03-76SF000098. 
Table I. Indexing of the visible $\mathrm{TiO}_{2} / \mathrm{ZnO}$ rings.

\begin{tabular}{rrrrl}
\hline $\mathrm{ZnO}$ & $\mathrm{L}(\mathrm{mm})$ & $\mathrm{d}(\mathrm{A})$ & Indexing & Comments \\
\hline 1 & 6.05868 & $2.927416\{10-10\}$ & Important strong ring $\perp$ to $(0001) \mathrm{ZnO}$ \\
2 & 10.67482 & $1.661506\{11-20\}$ & Important strong ring $\perp$ to $(0001) \mathrm{ZnO}$ \\
3 & 12.40587 & $1.429668\{20-20\}$ & Important strong ring $\perp$ to $(0001) \mathrm{ZnO}$ \\
4 & 16.44752 & $1.078356\{21-30\}$ & Important strong ring $\perp$ to $(0001) \mathrm{ZnO}$ \\
5 & 18.76193 & $0.945333\{30-30\}$ & Important strong ring $\perp$ to $(0001) \mathrm{ZnO}$ \\
6 & 21.78431 & $0.814177\{22-40\}$ & Important strong ring $\perp$ to $(0001) \mathrm{ZnO}$ \\
7 & 22.64976 & $0.783067\{31-40\}$ & Important strong ring $\perp$ to $(0001) \mathrm{ZnO}$ \\
\hline
\end{tabular}


Table II. Indexing of the $\mathrm{TiO}_{2} / \mathrm{ZnO} / \mathrm{Ag}$.

\begin{tabular}{cllll}
\hline $\mathrm{ZnO} / \mathrm{Ag}$ & $\mathrm{L}(\mathrm{mm})$ & $\mathrm{d}(\mathrm{A})$ & Indexed w/ FCC Ag & Comments \\
\hline 1 & 6.204611 & $2.858564\{110\}$ & Not Allowed $\Rightarrow \mathrm{ZnO}\{10-10\}$ ring \\
2 & 10.82003 & $1.639207\{112\}$ & Not Allowed $\Rightarrow \mathrm{ZnO}\{11-20\}$ ring \\
3 & 12.26161 & $1.446488\{220\}$ & Allowed Important strong ring $\perp$ to $\{111\} \mathrm{Ag}$ \\
4 & 18.90612 & $0.938124\{420\}$ & $\begin{array}{l}\text { Allowed, but probably this is the } \mathrm{ZnO}\{30-30\} \\
\text { ring. }\end{array}$ \\
5 & 21.22304 & $0.835709\{422\}$ & Allowed and $\perp$ to $\{111\}$ Ag if $\{-4,2,2\}$ type \\
\hline
\end{tabular}


Table III. Results from surface roughness analysis using AFM of Ag films $16 \mathrm{~nm}$ thick.

\begin{tabular}{|c|c|c|c|c|c|}
\hline Structure & $\begin{array}{l}\Re \\
(\Omega)\end{array}$ & $\varepsilon$ & $\begin{array}{l}\text { Roughness rms } \\
(\mathrm{nm})\end{array}$ & $\begin{array}{l}\text { Max Range } \\
(\mathrm{nm})\end{array}$ & $\begin{array}{l}\text { Total Surface } \\
\text { Area } S_{r}\left(\mu m^{2}\right)\end{array}$ \\
\hline $\mathrm{TiO} 2 / \mathrm{ZnO} / \mathrm{Ag}$ & 2.7 & .0488 & 0.442 & 4.324 & 4.013 \\
\hline $\mathrm{TiO} 2 / \mathrm{Ag}$ & 3.3 & .058 & 1.574 & 19.374 & 4.066 \\
\hline $\mathrm{TiO} 2 / \mathrm{ZnO} / \mathrm{Ag}$ & 2.7 & .0488 & 0.413 & 3.649 & 4.011 \\
\hline $\mathrm{TiO} 2 / \mathrm{Ag}$ & 3.3 & .058 & 1.499 & 16.132 & 4.039 \\
\hline
\end{tabular}


Table IV. Slopes and Intercepts from Figure 15, where $\delta \rho_{s p}$ is twice the slope and $\rho_{\text {bulk }}$ is the intercept.

\begin{tabular}{lcccc}
\hline & $\begin{array}{c}\delta \rho_{s p} \\
\left(10^{-16} \Omega-m^{2}\right)\end{array}$ & $\begin{array}{c}\delta \rho_{s p} \\
\left(10^{-16} \Omega-m^{2}\right)\end{array}$ & $\begin{array}{c}\rho_{\text {bulk }} \\
\left(10^{-8} \Omega-m\right)\end{array}$ & $\begin{array}{c}\rho_{\text {bulk }} \\
\left(10^{-8} \Omega-m^{m}\right)\end{array}$ \\
\hline sccm & TiO2 & $\mathrm{ZnO}$ & $\mathrm{TiO} 2$ & $\mathrm{ZnO}$ \\
0 O2 & 3.52 & 2.88 & 3.11 & 2.76 \\
17 O2 & -0.470 & -0.76 & 21.4 & 21.2 \\
17 N2 & 3.16 & 2.32 & 4.6 & 4.59 \\
50 N2 & 5.26 & 4.78 & 4.65 & 4.53 \\
\hline
\end{tabular}


Table V. Results of simplified modeling.

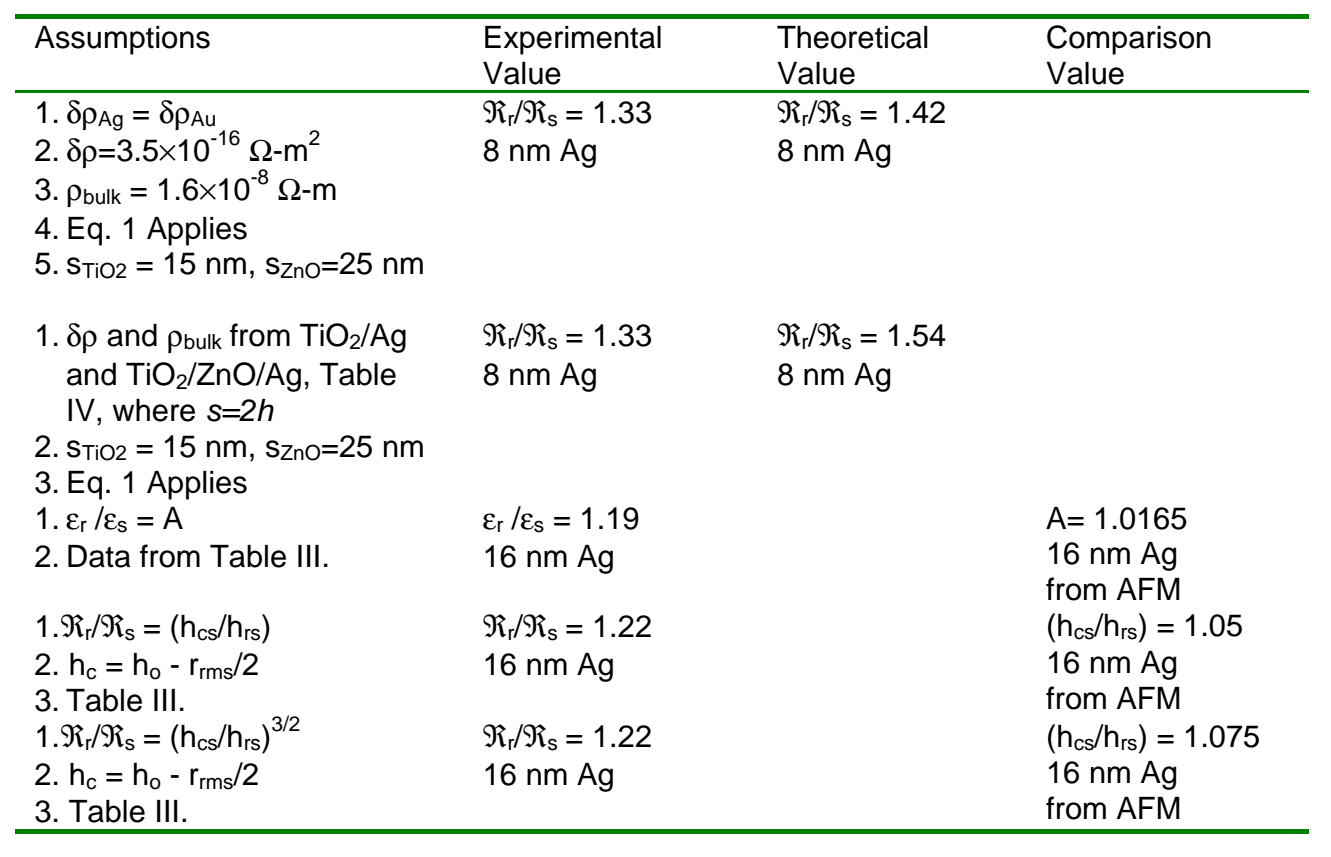




\section{REFERENCES:}

1. J. Szcyrbowski, G. Brauer, M. Ruske, H. Schilling, A. Zmelty, Thin Solid Films 351 254-259 (1999).

2. M. Ruske, private communication.

3. Varun V. Singh, Alexander H. King and Girish Dixit, Journal of Electronic Materials 26 (1997) 987-995.

4. I. Nakamichi, J. Sci. Hiroshima Univ. A 54, 49 (1990).

5. R.A. Brown, J. Phys. F Metal Physics 7, 1477 (1977).

6. G. Lormand, Scripta Met. 13, 27 (1979).

7. A.C. Hasson, Phys. Stat. Sol. 2, 551 (1970).

8. E. Van der Voort and P. Guyot, Phys. Stat. Sol. 47, 465 (1971).

9. M. Vergohl, et. al. J. Vac. Sci. Tech. A 18(4) 1632-37 (2000).

10. R.Dannenberg, S. Baliga, R.J. Gambino, A.H. King, A.P. Doctor J. Appl. Physics (1999) 86 514-523.

11. R. Dannenberg, A. Doctor, R.J. Gambino, 1996 Meeting of the IRIS Specialty Group on Infared Materials Proceedings, held 29,30 July 1996 National Institute of Standards \& Technology, Boulder CO. pp159-169.

12. E. Ando, et.al., Asahi internal development.

13. P. Garcia, Appl. Phys. Let. 58, 191 (1991).

14. P. Garcia J. Appl.Phys. 73, 6424 (1993).

15. Mehran Arbab, PPG Industries, US Patent 5,821,001 (1998).

16. J.Szczrbowski et.al. Solar Energy Materials 19 43-53 (1989). 
17. Professor Rainer Birringer, Department of Physics, Universitat des

Saarlandes, Professor Alexander King, Department Materials Science and Engineering, Purdue University.

18. Mehran Arbab, Thin Solid Films 381 (2000) 15-21.

19. Neil W. Aschcroft, N. David Mermin, Solid State Physics, Saunders College Publishing, New York, NY (1976).

20. CRC Handbook. 


\section{Figure Captions:}

Figure $1.50 \mathrm{~nm}$ thick amorphous $\mathrm{Si}_{3} \mathrm{~N}_{4}$ TEM grid. At the edge of the membrane is a transparent section of [001] Si that allows internal calibration for diffraction ring indexing.

Figure 2. Ag film grown on the underlayers given beneath the diffraction patterns. The dark ring on the right is $\{220\}$ implying the $\mathrm{Ag}$ film on $\mathrm{ZnO}$ is $\{111\}$ oriented. The spots are (400) Si used to calibrate the camera length.

Figure 3. Image left is $\mathrm{TiO}_{2} /\{0001\} \mathrm{ZnO}$ and the right is $\mathrm{TiO}_{2} /\{0001\} \mathrm{ZnO} /\{111\}$ Ag. The visible rings in these diffraction patterns are indexed in Tables I-II, respectively.

Figure 4. Bright field images of $\mathrm{Ag}$ on the indicated underlayers.

Figure 5. Dark field negative comparison of the Ag films on the indicated underlayers.

Figure 6. Discontinuous Ag film in the center of the TEM grid with the $\mathrm{TiO}_{2}$ underlayer. 
Figure 7. Behavior of sheet resistance predicted from a grain boundary resistivity of $3.5 \times 10^{-16} \Omega-m^{2}, C=2$, and an Ag thickness of $16 \mathrm{~nm}$. The sheet resistance of a bulk (single crystal) Ag film $8 \mathrm{~nm}$ thick would be $2 \Omega /$.

Figure 8. Electron diffraction pattern of amorphous $\mathrm{TiO}_{2}$.

Figure 9. AFM analysis of the surface roughness of $\mathrm{TiO}_{2} / \mathrm{ZnO} / \mathrm{Ag}$.

Figure 10. AFM analysis of $\mathrm{TiO}_{2} / \mathrm{Ag}$.

Figure 11. The emissivity vs. sheet resistance for $\mathrm{Ag}$ grown on $\mathrm{TiO}_{2}$ and $\mathrm{TiO}_{2} / \mathrm{ZnO} . h_{o}=16 \mathrm{~nm}$.

Figure 12. The sheet resistance of $\mathrm{Ag}$ on $\mathrm{ZnO}$ is consistently lower than on $\mathrm{TiO}_{2}$ for the same amout of deposited material. $h_{0}=16 \mathrm{~nm}$.

Figure 13. For both underlayers $\mathfrak{R}_{f} / \Re_{o} \cong\left(h_{o} / h_{f}\right)^{3 / 2} . h_{o}=16 \mathrm{~nm} . \Re_{o}=3.3$ and 2.66 $\Omega /$ for $\mathrm{Ag}$ on the $\mathrm{TiO}_{2}$ and $\mathrm{ZnO}$ underlayers, respectively.

Figure 14. Emissivity versus film thickness ratios for both underlayers. $h_{0}=16$ $\mathrm{nm}$.

Figure 15. $\Re h$ vs. (2/h) curves for various mixtures of $\mathrm{Ar} / \mathrm{N}_{2}$ and $\mathrm{Ar} / \mathrm{O}_{2}$ process gases. 


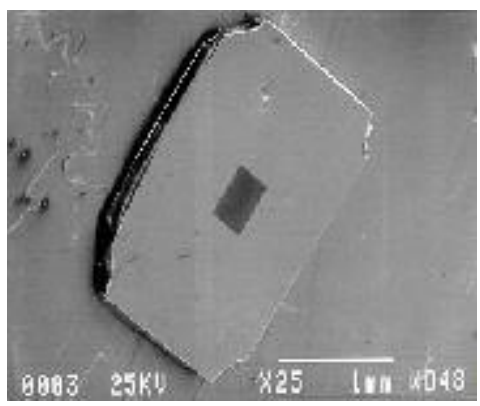

Figure 1. 


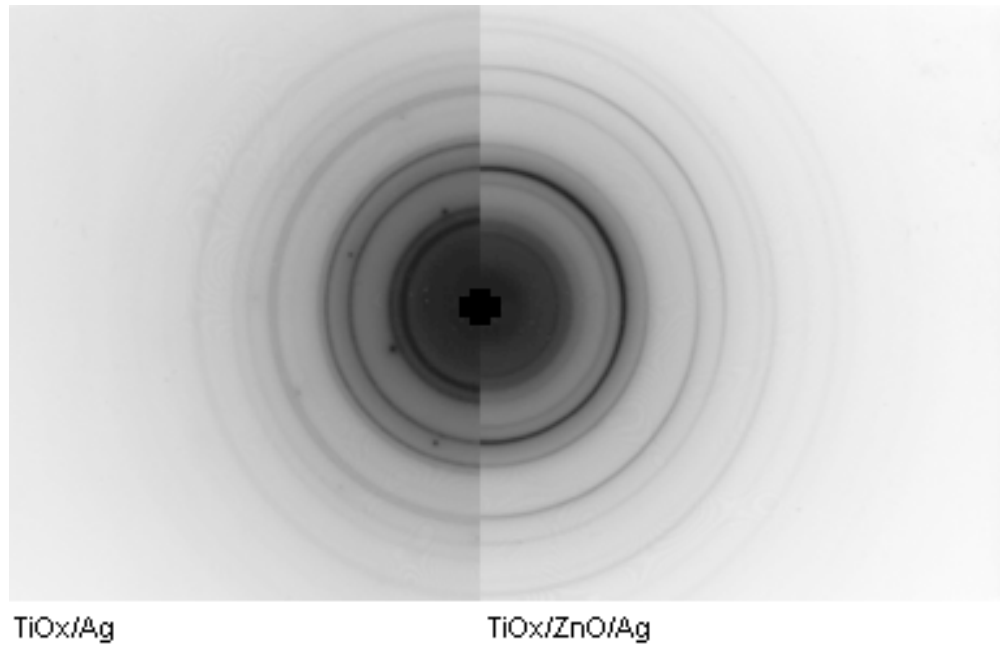

Figure 2. 


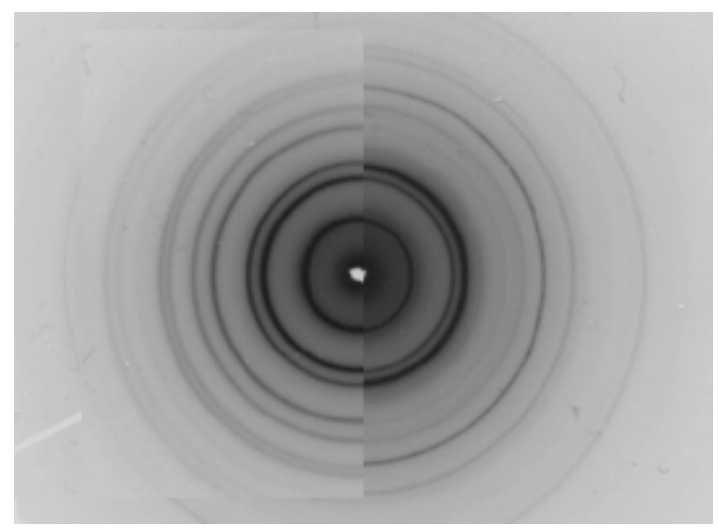

Figure 3. 


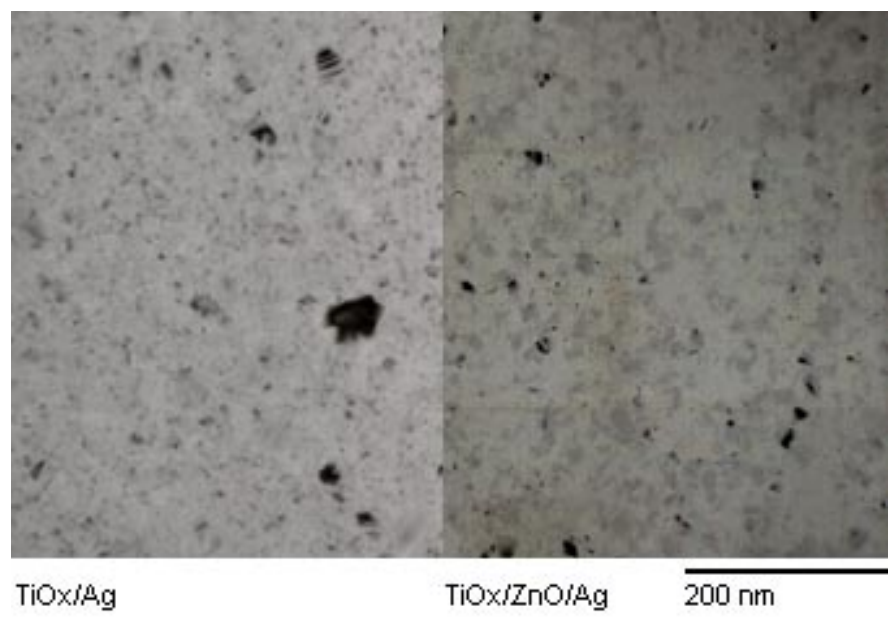

Figure 4. 


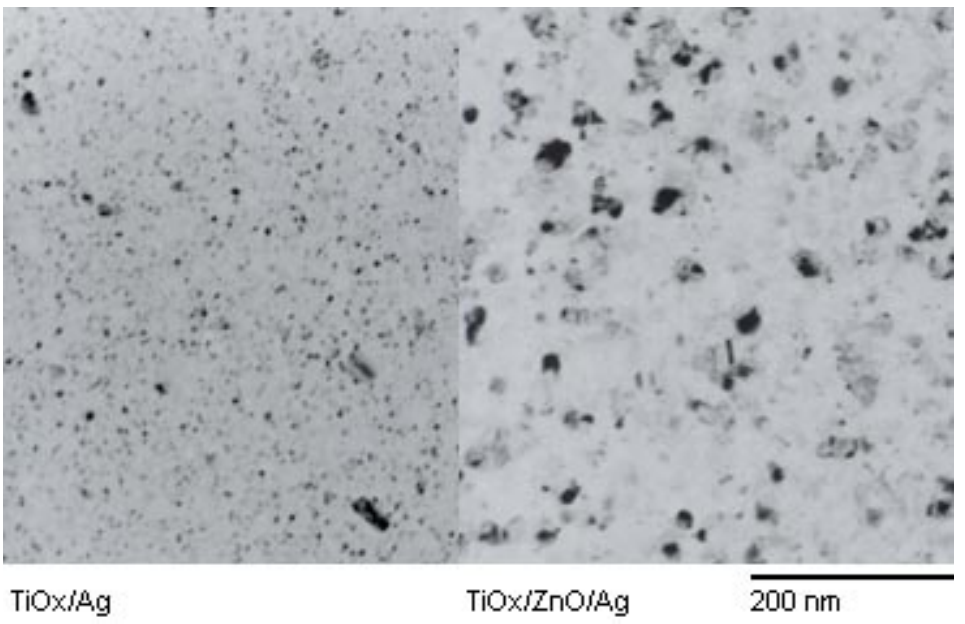

Figure 5. 


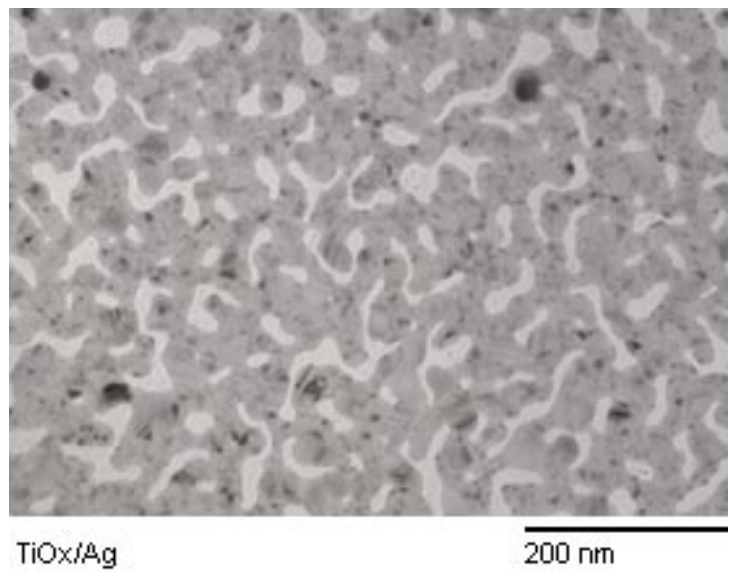

Figure 6. 


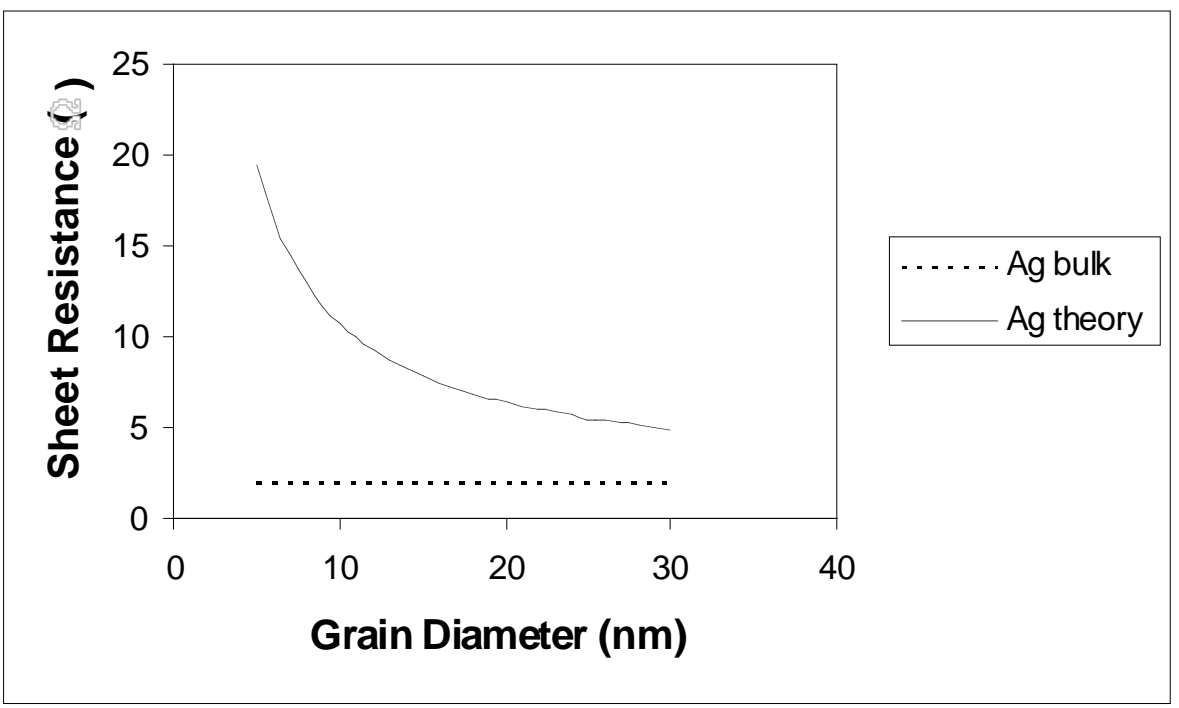

Figure 7. 


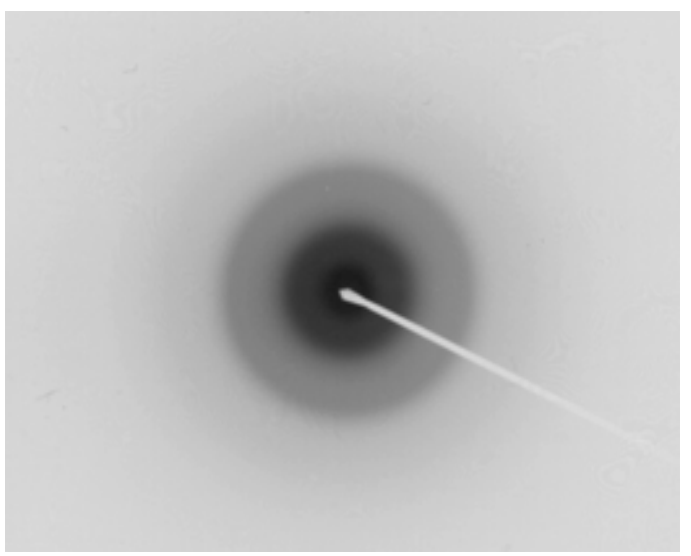

Figure 8. 


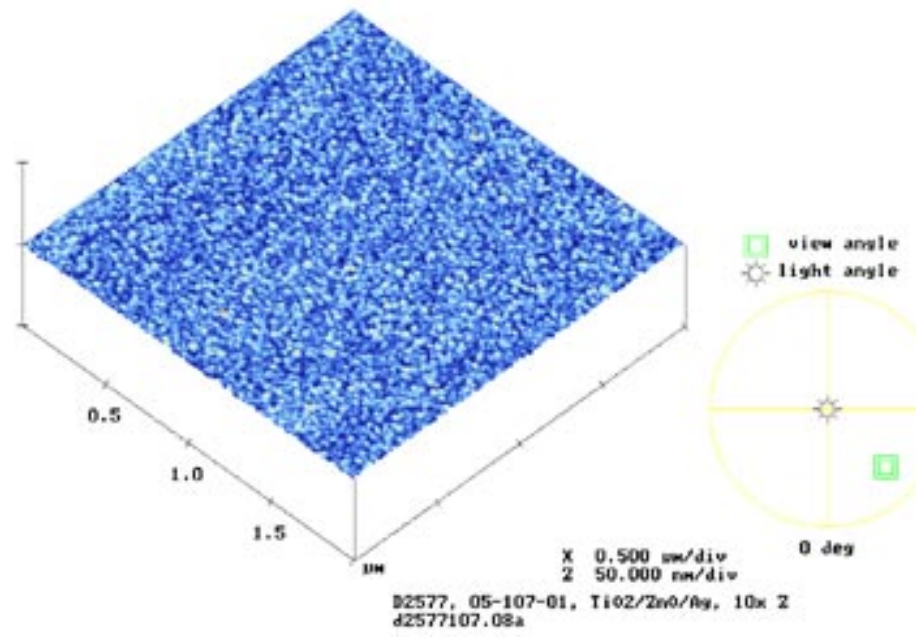

Figure 9. 


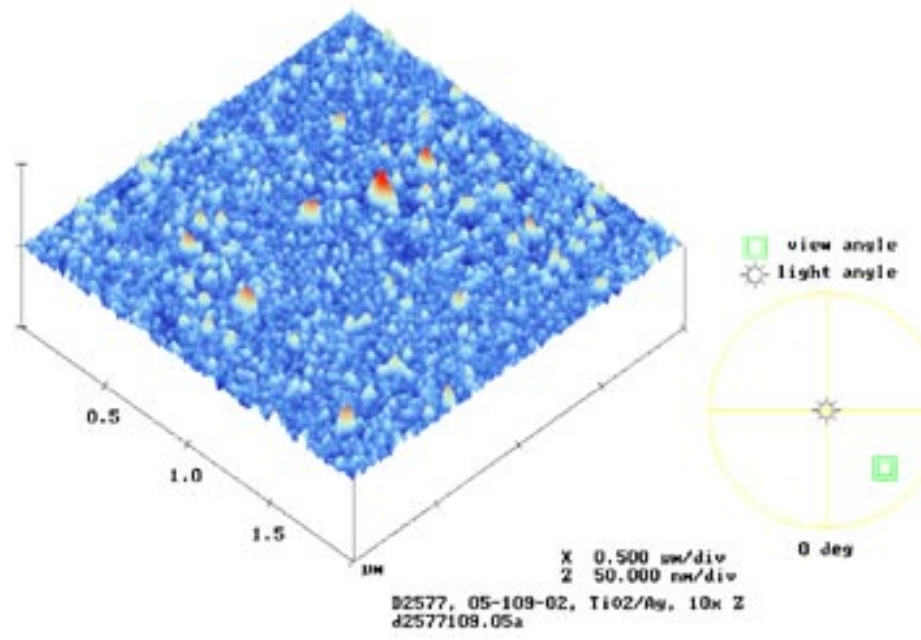

Figure 10. 


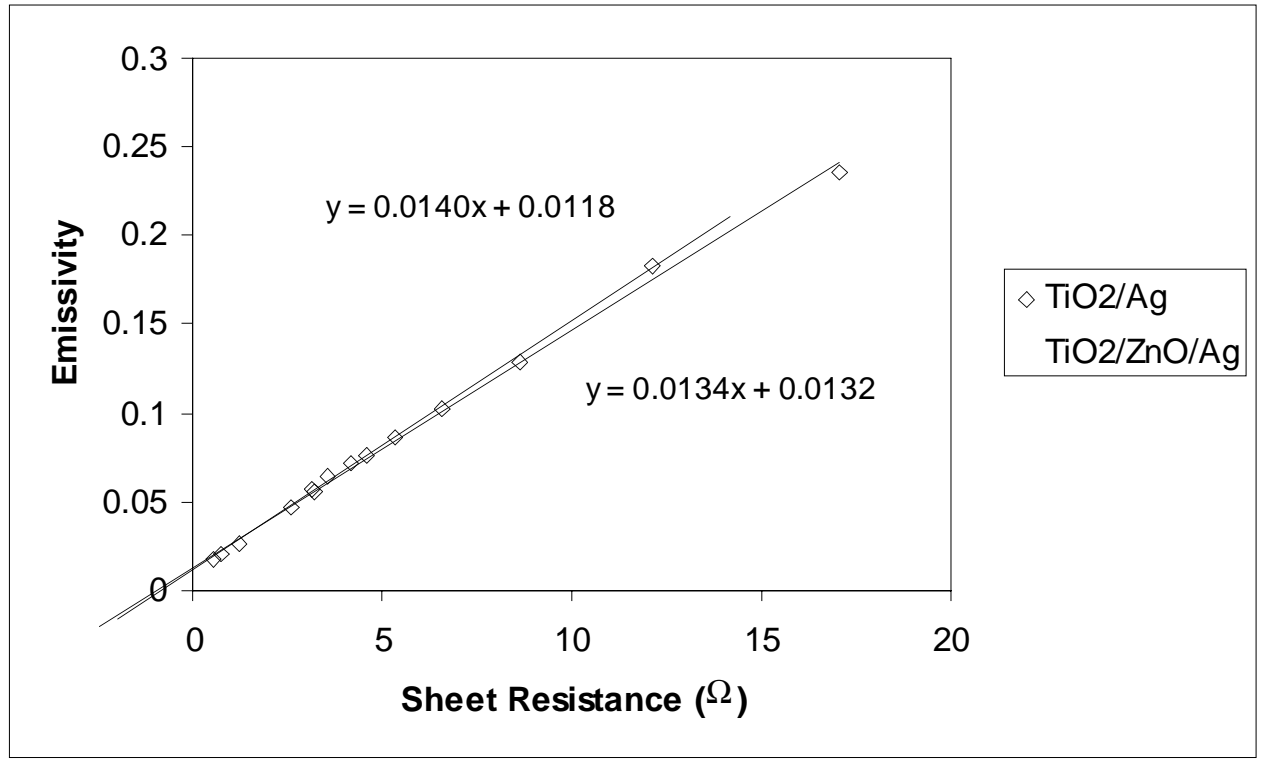

Figure 11. 


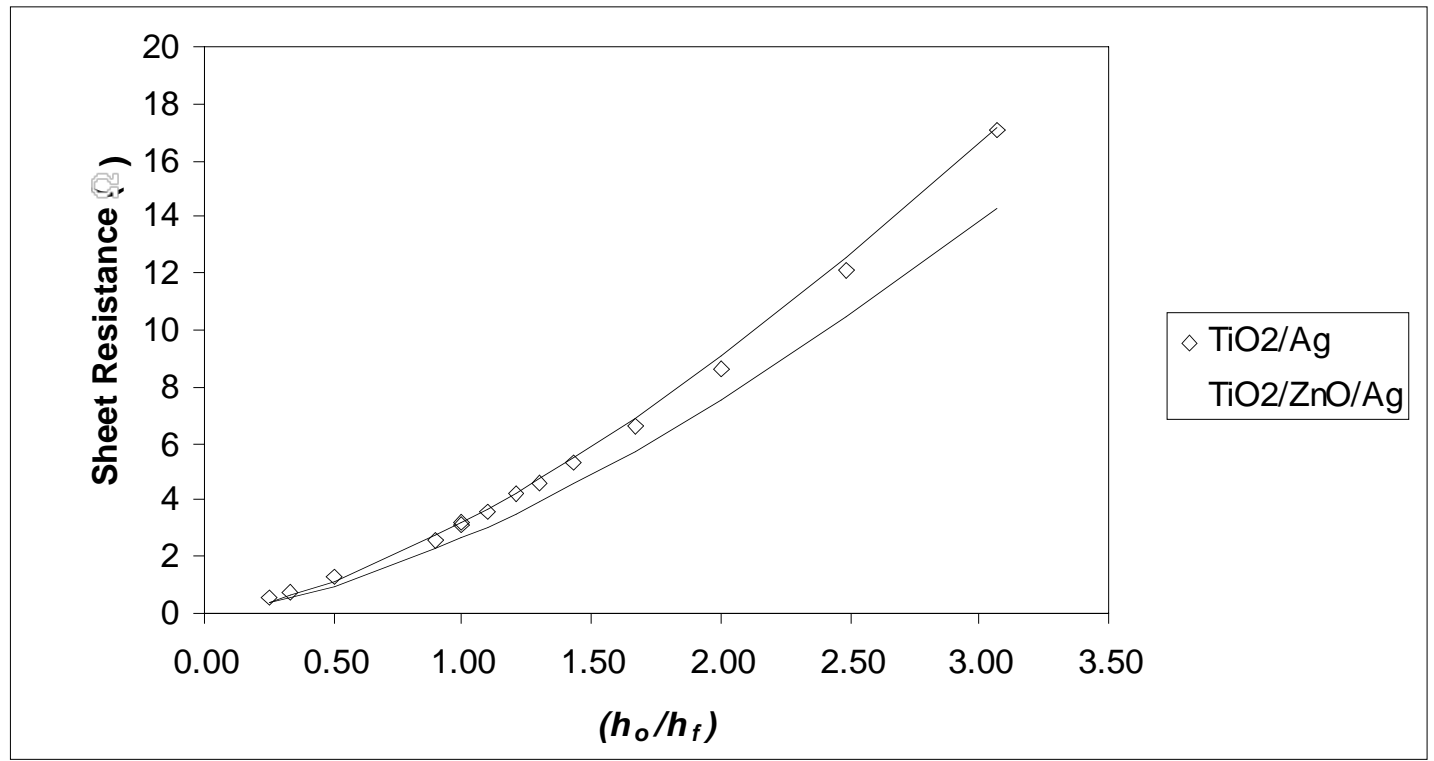

Figure 12. 


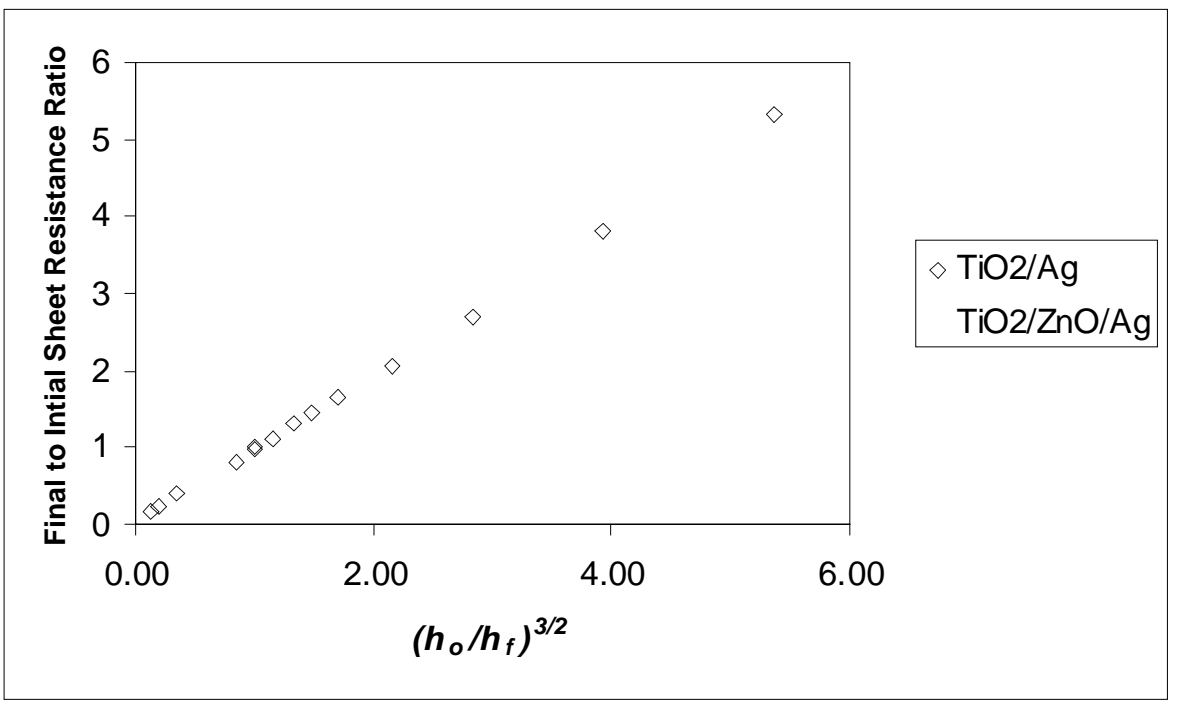

Figure 13. 


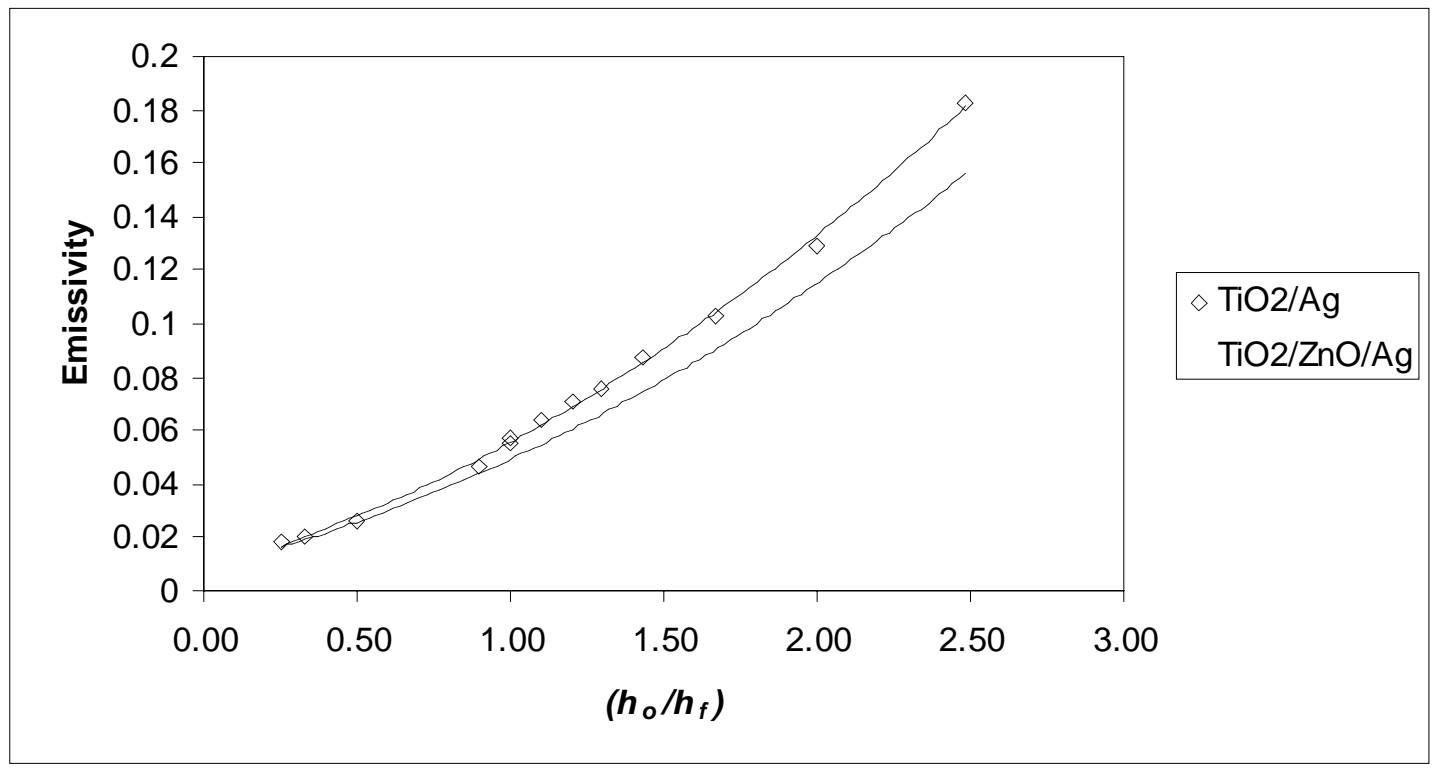

Figure 14. 


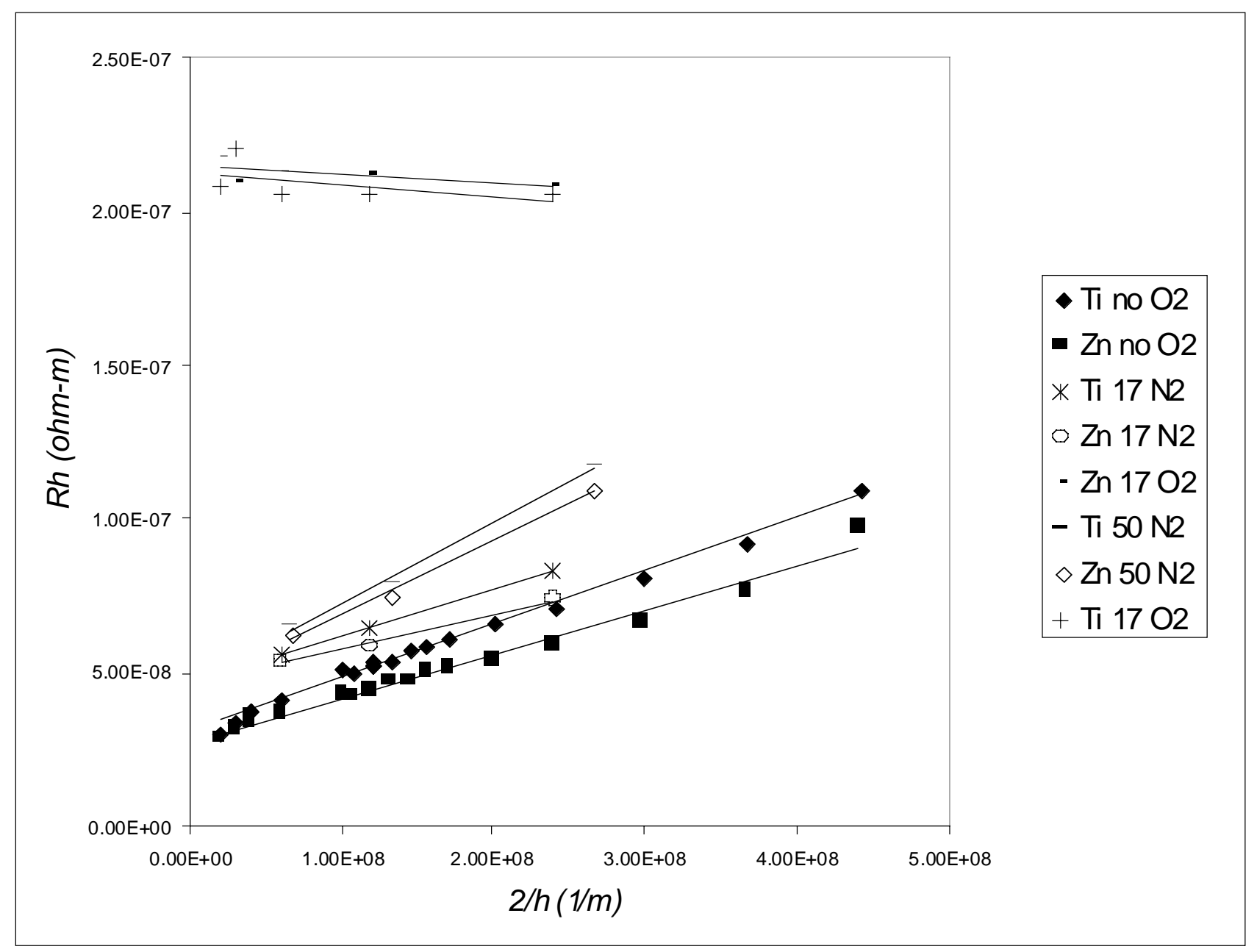

Figure 15. 